\title{
DISSIMILARITY OF INNER AND OUTER PROTOPLASMIC SURFACES IN VALONIA.
}

By W. J. V. OSTERHOUT, E. B. DAMON, AND A. G. JACQUES.

(From the Laboratories of The Rockefeller Institute for Medical Research.)

(Accepted for publication, September 20, 1927.)

The protoplasm of Valonia macrophysa forms a delicate layer, only a few microns thick, which contains numerous chloroplasts and nuclei. The outer surface is in contact with the cell wall, the inner with the sap of the large central vacuole. As far as microscopic observation goes, there is no difference between the inner and outer surfaces of the protoplasm, but the measurements of potential differences described in this paper indicate that they are not alike.

These measurements were made in the following manner. A fine glass capillary, filled with cell sap ${ }^{1}$ or artificial sap, ${ }^{2}$ was inserted in the cell (Fig. 1) which was connected to a Compton electrometer in the manner shown in Fig. 2. The calomel electrodes, $A_{1}$ and $A_{2}$, were filled with saturated $\mathrm{KCl}$ and dipped into the beakers $B$ and $E$ containing saturated $\mathrm{KCl}$ solution. They were introduced into the chain simply to protect the solution in $C$ and $D$ from excessive contamination by the saturated solution of $\mathrm{KCl}$. For the same reason the solution in $H$ was always maintained at a higher level than in $B$, and the solu-

${ }^{1}$ The sap has the following composition, expressed as per cent (molar) of halide (which is about $0.6 \mathrm{M}$ ):

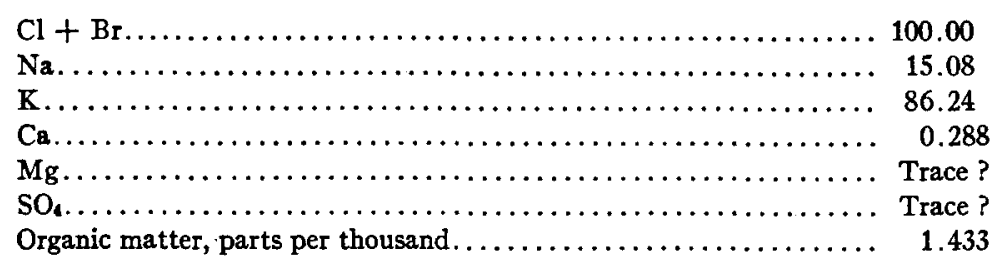

Cf. Osterhout, W. J. V., J. Gen. Physinl., 1922-23, v, 228.

2 This contained $\mathrm{NaCl}, \mathrm{KCl}$ and $\mathrm{CaCl}_{2}$ in the same proportions as the natural sap. Its halide content was $0.61 \mathrm{M}$. 
tion in $D$ at a higher level than in $E$, so that any flow in the strings would be away from $C$ and $D$. In the chain $C$ acted as a support for the cell. The beaker $D$ contained the sap which was in contact with the outside of the cell. The sap in $D$ was occasionally natural sap, but artificial sap was usually employed since it was more convenient and gave the same results as the natural sap.

The beakers $B, D$ and $E$ were supported on dry inverted beakers and the cell holder $C$ on a block of paraffin. All parts of the measuring apparatus (electrometer, switches, calibrating potentiometer, etc., as well as the chain itself) were placed on metal plates (copper or zinc)



FIG. 1. Diagram of the main circuit in a cell of Valonia macrophysa impaled on a capillary and in contact with a solution at its lower surface $(W$, cell wall; $P$, protoplasm). which were connected together and grounded, and which acted as a shield. The apparatus and its connections were, of course, carefully insulated from the shield. This is the method recommended by White. ${ }^{3}$ Total shielding was not attempted. The calomel electrodes were connected through mercury wells to a Compton electrometer.

The electrometer was read by means of a lamp and scale, and was calibrated frequently during the work by means of a potentiometer. As the curve obtained by plotting voltage against deflection was not a straight line, the deflections falling off at the higher voltages, calibration was carried out at a voltage somewhere near the potential difference being measured at the time. The sensitivity was between

1.5 and 2 meters per volt. By means of a double pole double throw switch it was possible to have the needle swing in either direction from zero when a potential of the same polarity was applied. This was useful in eliminating the errors due to the shifting of the zero point, as toth right and left swings were always read and the average recorded. This also permitted us to detect open circuits and high resistances in the circuit, as when these occurred the swings were either very unsymmetrical or else were both on the same side of the zero point.

${ }^{3}$ White, W. P., J. Am. Chem. Soc., 1914, xxxvi, 2011. 
The condensation of moisture on the glass plate, on which the train stood, was a source of considerable trouble on humid days. For this reason several plates were in use and were dried out over a hot plate just before use.

The cell holder $C$ consisted simply of a bottle fitted with a two hole rubber stopper through one hole of which was passed a tube terminating at its upper end in a funnel, $H$ : in the other hole there was a tube ending in a fine capillary on which the cell was impaled in the

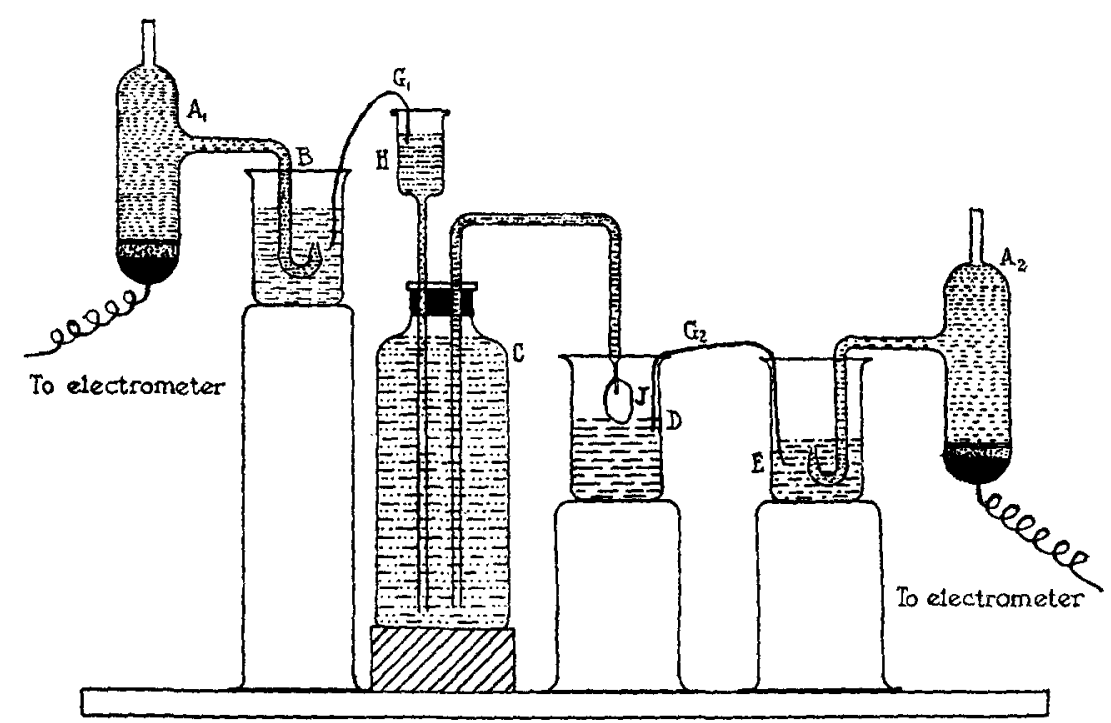

Fig. 2. Showing the manner in which the cell. $J$, is connected to the electrometer. The bottle, $C$, and the capillary on which $J$ is impaled are filled with artificial sap.

manner indicated in Fig. 2. In use the bottle and tubes were filled with artificial sap, thus affording a connection to the inside solution of the cell. The sap in $H$ was allowed to stand at such a level as to produce 2 to 3 inches of hydrostatic pressure at the tip of the capillary. In this way the cell was kept inflated. It is worthy of note that no leak occurred at the puncture at this or even at considerably higher pressures in the case of those cells which continued to live after being impaled. It will be seen that the cell in this arrangement hung free 
from the tip of the capillary. No support was given it from below. This arrangement proved to be very satisfactory. Early in the work a considerable number of cells were lost by being shaken from the tip when the bottle was being moved. As our technique improved the losses from this cause were reduced to negligible proportions. However it was desirable to devise some method of supporting the cell from below, especially for prolonged measurements where the potential difference was to be measured from day to day for some time. Under these circumstances considerable handling of the cell holder and consequent shaking of the cell could not be avoided. To meet this situation the arrangement illustrated in Fig. 3 was devised.

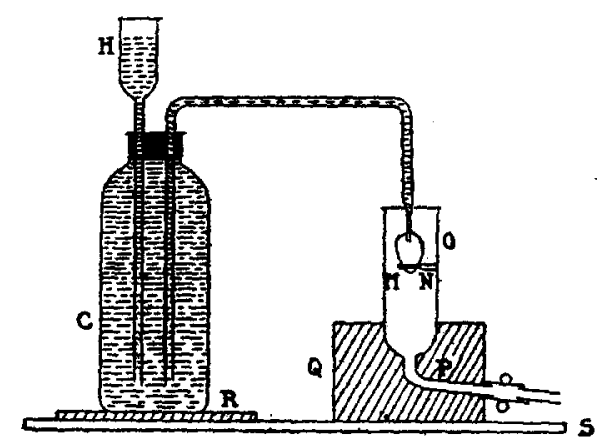

FIG. 3. Shows the ring $M N$, used to support the cell.

The cell holder $C$ was as described above. The support for the bottom of the cell consisted simply of a glass ring, $M$, made of a $1 \mathrm{~mm}$. glass rod, the opening of the ring being 3 to $5 \mathrm{~mm}$. in diameter. The ring was sealed to a short piece of glass rod $N$ and this in turn was sealed to the wall of the glass tube $O(35 \mathrm{~mm}$. in diameter) in such a way that the ring lay in a horizontal plane near the center of $O$. The tube $O$ was drawn out at the lower end and the narrow tube $P$ sealed on to form a drain. This was closed by means of a rubber tube and pinch-clamp. This part of the apparatus was imbedded in the manner indicated in the block of paraffin $Q$ and this in turn was attached to the glass plate $S . \quad C$ was held in position on the plate by a thin layer of paraffin $R . \quad C$ and $O$ were fixed to the plate in such a manner that the cell rested on the ring $M$ but was not under enough pressure to 
cause the cell to collapse even slightly. This adjustment was somewhat troublesome. It was accomplished in the following way. With $C$ free from the plate, the cell was impaled. Then the capillary tube was moved up or down in the rubber stopper slightly until, when $C$ was placed on the thin layer of paraffin $R$, the cell did not quite touch the ring. The layer of paraffin was then melted by heating the glass plate from below and in most cases the bottle settled so as to bring the bottom of the cell into the required position just on the ring. When

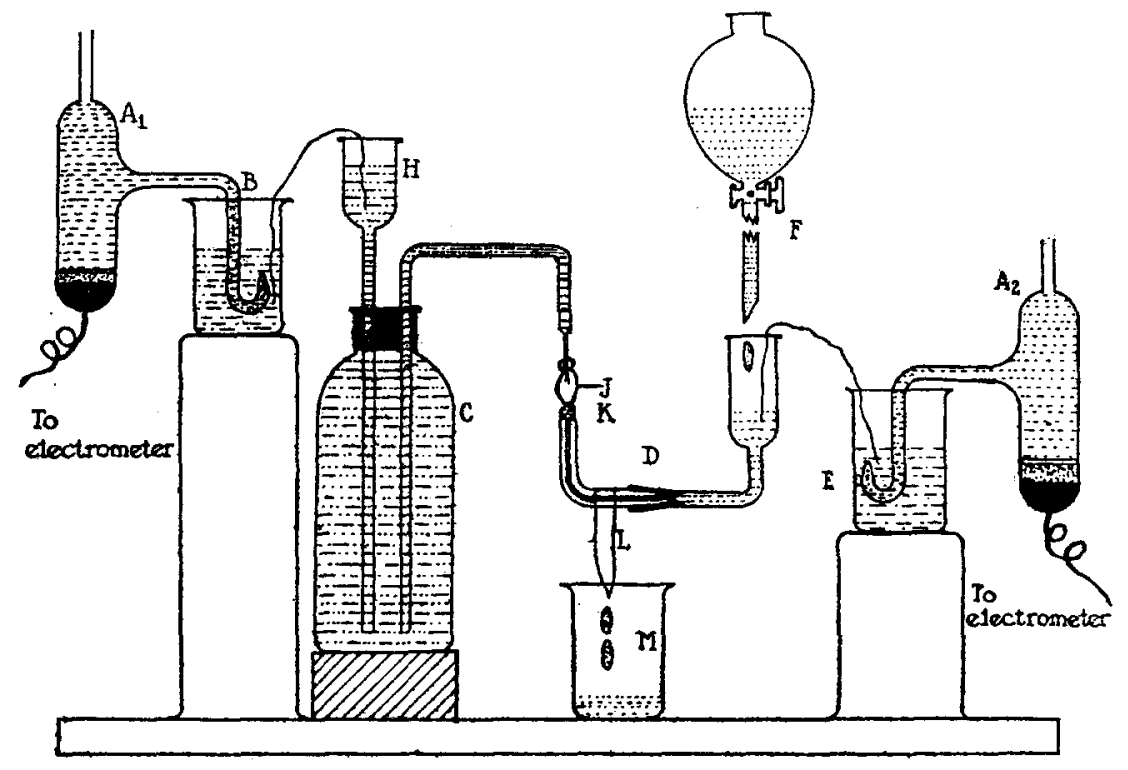

FIG. 4. Shows the manner of applying a flowing junction at $K$ : the current of solution from $F$ overflows at $K$ and is carried by a strip of filter paper, $L$, to the waste beaker, $M$.

the paraffin hardened on cooling it held $C$ in position. This part of the chain, cell and support, which was also the solution holder, was a fairly rigid unit. It could be moved without shaking the cell. In practice a number of these units were made up so several experiments could be carried out simultaneously.

In both the chains described above the solution applied to the outside of the cell was stationary. In some experiments (particularly those where the external solution differed from the internal) a flowing 
junction was used. The apparatus with this modification introduced is illustrated in Fig. 4. In this train the beaker $D$ of Fig. 2 was replaced by the U-tube $D$ of Fig. 4 . This U-tube (built in two parts with a ground glass joint for ease in emptying and cleaning) consisted of a wide right arm and a capillary left arm, the end of the thick walled capillary $K$ being ground roughly plane. The required solution was dropped from the funnel $F$ into the wide arm at such a rate that a slight head was maintained on the right-hand side of the U-tube. The rate of flow from the U-tube was of course controlled by the length and bore of the capillary left arm. The drops of solution overflowing from $K$ were led into the waste beaker $M$ by means of the strip of filter paper $L . \quad C$, the cell holder, was placed in such a position that the cell $J$ did not quite touch the drops rising in $K$. Then when $J$ was lowered very slightly the liquid was drawn up and held in contact by surface tension. In this way a current of solution came into contact with a small area of the cell. The connection between $B$ and $H$ and $D$ and $E$ was made as before by means of damp strings. A further modification permitting the use of a supporting ring with the flowing junction is shown in Fig. 5.

The operation of impaling the cell so that it would cling to the capillary and live was not difficult provided certain conditions were fulfilled. It was almost essential that the capillary should be very fine, with sides as nearly parallel as possible, and that the glass at the tip should be very thin. It was also found advantageous to break off the tip of the capillary on a slant. In impaling the cell a brisk stream of liquid was forced out of the tip by blowing in at $H$ and the cell was then slipped on to the capillary with one quick motion. Proceeding this way very few of the cells showed any sign of leakage or loss of their original contents. In some cases a small amount of natural sap was drawn up into the capillary before impaling the cells. This was to prevent the possibility of the cell sap being contaminated by artificial sap. However, as no ill effect was noticed in the experiments where this precaution was not taken it was abandoned.

Valonia macrophysa, as it occurs in Bermuda, is found in clumps containing many cells. Many of the cells used had one or more buds but in other cases they were lacking. However, in all the experiments impaling was carried out in such a way that the buds did not come 
into the circuit (Fig. 6). The cells employed 'varied from 1 to 3 inches in length.

The object of the experiments was to measure the potentials in the circuit indicated by the dotted line in Fig. 1. But since the cell wall was imbibed with sea water and was wet on the outside the possibility of an electrical leak at the puncture must be considered. Such a leak would be equivalent to connecting the inside and outside of the cell by the dotted line in Fig. 7. If the liquid leak at the puncture were marked we should expect the electrical leak to be serious and as a result there should be no measurable potential difference. If, on the other hand, the leak were very slight then we should

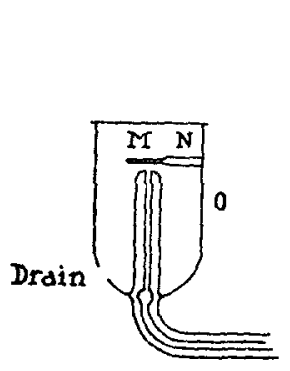

FIG. 5.
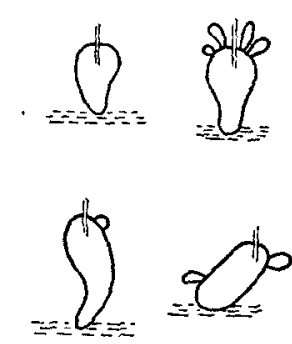

FIG. 6 .
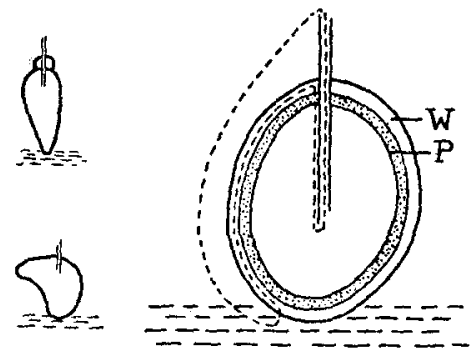

FIG. 7.

Frg. 5. Shows the manner of applying a flowing junction (as in Fig. 4) when the cell is supported by a ring, $M N$.

FIG. 6. Shows the manner of impaling cells on the capillary.

Fig. 7. The dotted line shows the short circuit in case of a leak at the capillary. $W$, cell wall; $P$, protoplasm.

expect considerable resistance in this short circuit and as a result there should be a measurable potential difference in the circuit through the wall. This would be less than the actual potential difference between the internal and external solutions. Now as has been pointed out above no liquid leak could ever be detected in the case of those cells which lived. On the other hand, considerable information was collected concerning the electrical leak at the puncture during the course of over 100 preliminary experiments. These experiments will first be described and discussed and then their bearing on the question of the electrical leak will be considered. 
These experiments were carried out with the object of finding out whether a living cell always gave a positive potential against its own sap, and, incidentally, against sea water. At this point it is desirable to explain a convention adopted in this paper: the potential stated is always that of the inside of the cell. Thus 28 millivolts plus means that the inside of the cell was 28 millivolts more positive than the external solution bathing the cell, i.e. the positive current tends to flow from the capillary through the electrometer to the solution in contact with the outside of the cell. In these preliminary experiments the cell was pierced and the potential difference at once measured against sap and against sea water. The cells were then allowed to stand in sea water overnight, impaled on the capillary, and the two measurements were repeated the next day. The cells were again returned to sea water overnight and further measurements made. This was repeated as long as the cell lived, the intervals between measurements being gradually increased. The criterion for death in these experiments was a change in the arrangement of the chloroplasts, as observed with the naked eye or with a small magnifying glass. The cells immediately after being impaled could be divided into two groups: $(A)$ the internal solution was positive against sea water outside and more positive against artificial or natural sap outside; $(B)$ the internal solution was either at the same potential or very slightly negative to sea water, and at the same potential as the external sap. After standing in sea water overnight, cells of the $A$ group either gave a positive potential difference against sea water outside and a still more positive potential difference against natural and artificial sap: or else the internal solution was at the same potential or slightly negative to the external sea water, and at the same potential as the artificial sap. In the former cases the cells were definitely alive. In the latter cases the cells were all dead: the chlorophyll layer was interrupted or completely broken up. Cells of the $B$ group, after standing in sea water overnight, gave a positive potential difference against sea water outside and a greater positive potential difference against natural or artificial sap or else they gave little or no negative potential difference against sea water outside and no potential difference against sap outside. As in the case of the $A$ cells on the 2nd day, those cells which were positive against sap and sea water were alive 
while those which were not positive were dead. Many of the cells lived several days and some of them a month or more. From these experiments it seemed fair to conclude that normally the internal solution is positive to sea water outside and still more positive to sap. ${ }^{4}$

There was no difficulty in accounting for the behavior of those cells of Group $A$ which on the 2nd day gave no measurable potential differences since they were dead, but with regard to those cells of Group $B$ which on the 2 nd day gave positive potentials against sea water and sap the hypothesis was advanced that the leak around the capillary had been eliminated by the formation of an "electrical seal" and consequently the disturbing short circuit had disappeared. To investigate this electrical seal a further series of experiments was carried out.

In these experiments a number of cells were impaled and the potentials of the internal solution were at once measured against sea water, first with the cells just in contact with the sea water and then with the cells completely immersed. Before being measured the cells were allowed to stand in sea water impaled on the capillary for periods ranging from 32 hours to 11 days. It was anticipated that where the liquid leak was considerable the measured potential in both cases would be zero or very small and that where the leak was less there would be a measurable plus potential with only the tip immersed and that this would fall almost or quite to zero with the whole cell immersed. On the other hand, if a cell could so cling to the capillary as to offer very great resistance to the passage of current at the puncture, we should anticipate positive potentials in both readings and the

4 With cells of Group $A$ the addition of a small amount of a toxic non-electrolyte to the external solution causes marked characteristic changes in the potential difference, the potential changing, after a few seconds, to that observed with cells known to be dead; while with cells known to be dead already, addition of chloroform or formaldehyde has no effect on the potential difference. This is an especially useful criterion of injury in cases where the applied solution is itself toxic. Cells killed by such solutions do not always show obvious signs of injury at once, and we may often be in doubt as to whether a measured potential is characteristic of the living or the dead cell. Addition of a small quantity of chloroform or formaldehyde solves the problem: if no change in the potential difference occurs, we know that the cell was dead; if a change does occur, the cell must have been alive, although possibly injured. 
more perfect the seal at the capillary the more closely they should agree. As Table I shows, all those cells which were freshly impaled gave smaller potential differences when immersed than when just touching the sea water. On the other hand, those cells which remained alive in sea water for long periods gave nearly the same result with both kinds of measurement.

Obviously the error due to a short circuit can be almost completely eliminated by allowing the cell to stand in sea water impaled on the capillary. In the following work this was always done and before each experiment the seal of each cell was tested by measuring the potential difference against sea water both when the tip alone was in

TABLE I.

\begin{tabular}{|c|c|c|c|}
\hline Cell No. & $\begin{array}{l}\text { Time on capillary before } \\
\text { measurement }\end{array}$ & $\begin{array}{l}\text { Potential difference. } \\
\text { Only tip immersed }\end{array}$ & $\begin{array}{l}\text { Potential difference. } \\
\text { Whole cell immersed }\end{array}$ \\
\hline 1 & Newly impaled & 9.3 plus & 3.2 plus \\
\hline 2 & “ & 6.5 " & $1.0 " 6$ \\
\hline 3 & “ & 3.3 “ & 0.7 minus \\
\hline 4 & $" 6$ & 7.2 ، & 0.4 ، \\
\hline \multirow[t]{2}{*}{5} & 8 days & 5.2 " & 4.9 plus \\
\hline & $9 "$ & $4.4 "$ & 4.4 \\
\hline \multirow[t]{2}{*}{6} & $11 ،$ & $4.6 “$ & $4.0 "$ \\
\hline & $12 "$ & $5.8 “$ & $5.9 "$ \\
\hline \multirow[t]{2}{*}{7} & 54 & $4.6 "$ & $5.0 \%$ \\
\hline & $6 " 6$ & $4.6 "$ & 4.8 “ \\
\hline 8 & $32 \mathrm{brs}$. & 4.5 “ & 4.9 " \\
\hline 9 & 6 days & $4.5 "$ & $5.1 “$ \\
\hline
\end{tabular}

the solution and when the whole cell was immersed. Only those cells which gave satisfactory agreement of these two measurements were used in further experiments. It was observed in the case of those cells which had a good seal that a ring of dark material had been deposited at the puncture. That a cell is capable of healing itself to the extent of filling punctures is proved by our experience with certain cells which accidentally fell from the capillary into sea water. In several of these cases the cell continued to live and became as turgid as an unpunctured cell. The puncture was seen to be filled with a dark material which projected from the wall perhaps as much as half a millimeter and had the appearance of a tiny solid black plug. In a few other cases 
where a very fine capillary was used the capillary became plugged. The cell on the capillary became as hard as an unpunctured cell.

Possible sources of error due to diffusion potentials in the strings, stray currents, lack of balance between the calomel electrodes, etc., were found to be too small to merit consideration. At frequent intervals $C$ was removed from the chain and a direct connection was made from $B$ to $D$ by means of string $G_{1}$ (Fig. 2). The observed potential difference was always either zero or at the worst slightly negative on the left.

The experiments were carried out in Bermuda at room temperature which varied from $15^{\circ}$ to $20^{\circ} \mathrm{C}$. But the variation in any one set of experiments was not over $3^{\circ} \mathrm{C}$.

When the potential difference is measured in this way we have the chain:5 sap | protoplasm / sap. Since this chain appears to be symmetrical we should expect its electromotive force to be zero. We find, however, a value of 14.5 millivolts, ${ }^{6}$ the inside of the cell being positive to the outside (i.e. the positive current tends to flow through the electrometer from the capillary to the solution in contact with the outside of the cell). We must therefore conclude that the proto-

${ }^{5}$ The cell wall is omitted since it does not seem to play a part in the results now under consideration. For a discussion of the rôle of the cell wall and the underlying principles governing the production of potential differences in these cells see Osterhout, W. J. V., J. Gen. Physiol., 1927-28, xi, 83.

${ }^{6}$ This is the average of 100 determinations giving the following figures:

\begin{tabular}{|c|c|c|}
\hline \multicolumn{3}{|l|}{ Minimum potential difference } \\
\hline Maximum " " & 38.0 & “ \\
\hline Mean of 100 experiments ..... & 14.5 & “ \\
\hline Average deviation from the mea & 3.5 & “ \\
\hline robable error... & 0.3 & “ \\
\hline
\end{tabular}

" " expressed as per cent of the mean....... 2.1

In an earlier paper by one of us (Osterhout, W. J. V., J. Gen. Physiol., 1924-25, vii, 561) it was stated that the arrangement shown in Fig. 1 gives very little potential difference when sea water is in contact with the outside of the cell. More recently Taylor and Whitaker (Taylor, C. V., and Whitaker, D. M., Carnegie Institution of Washington, 1925-26, xxv, 248) have obtained a similar result. There is no assurance that an electrical seal was formed in these experiments. When such a seal is obtained we find a potential difference of about 5 millivolts. 
plasm is not symmetrical and this raises the question of its probable structure.

It has been suggested by one of us that the protoplasm may be composed of layers, the simplest assumption being that the outer surface, $X$, and the inner surface, $Y$, are probably non-aqueous, while between them lies an aqueous layer, $W$. If we adopt this as a working hypothesis, we may consider that we have the chain

$$
\text { sap }|X| W|Y| \text { sap }
$$

and that $X$ and $Y$ are unlike, which would give an unsymmetrical chain. In this way we might explain the source of the observed potential difference since it has been shown by Cremer, ${ }^{7}$ and by Beutner, ${ }^{7}$ that when two different liquids immiscible with water are brought into contact with aqueous solutions so as to make a chain similar to the one we are discussing, a potential difference may result. Mond ${ }^{\circ}$ obtained similar results with chains consisting of acid and alkaline gelatin or of euglobin and casein.

It would therefore appear that the inner and outer surfaces of the protoplasm are quite different. It has recently been suggested by one of us that this must be the case since certain substances are apparently able to penetrate the outer surface but not the inner.

These views are in line with experiments ${ }^{9}$ on the marine alga Griffithsia which indicate a difference in behavior of the two surfaces, and in harmony with the earlier work of de Vries ${ }^{10}$ if his results may be interpreted to mean that the inner and outer surfaces do not act alike.

It may be added that Höber, ${ }^{11}$ in discussing the current of injury in muscle, mentions the possibility that the inner and outer surfaces of the protoplasm may be unlike. But since there is no vacuole in such cells it is evident that the situation is quite different from that

${ }^{7}$ Cf. Beutner, R., Die Entstehung elektrischer Ströme in lebenden Geweben, Stuttgart, 1920.

${ }^{8}$ Mond, R., Arch. ges. Physiol., 1924, cciii, 247.

'Osterhout, W. J. V., Science, 1913, xxxviii, 408.

${ }^{10}$ de Vries, H., Jahrb. wissensch. Bot., 1885, xvi, 465. See also Küster, E., Ber. bot. Ges., 1909, xxvii, 589; Arch. Entweklngsmechn. Organ., 1910, xxx, pt. 1, Festschrift für Wilhelm Roux, 351; Z. Bot., 1910, ii, 689.

${ }^{11}$ Höber, R., Physikalische Chemie der Zelle und der Gewebe, 6th edition, Leipsic, 1926, 732. 
described in this paper. The difference of which Höber speaks can hardly be between $X$ and $Y$ (as discussed above), but perhaps rather between the inner and outer surfaces of $X$.

If it is true that in a thin layer of protoplasm the two surfaces may be so different, it is evident that our ideas regarding the factors that determine the structure of protoplasm are in need of revision. The subject deserves further investigation and will be discussed in subsequent papers.

SUMMARY.

The protoplasm of Valonia macrophysa forms a delicate layer, only a few microns in thickness, which contains numerous chloroplasts and nuclei. The outer surface is in contact with the cell wall, the inner with the vacuolar sap. As far as microscopic observation goes, these two surfaces seem alike; but measurements of potential difference indicate that they are decidedly different. We find that the chain

sap | protoplasm | sap

gives about 14.5 millivolts, the inner surface being positive to the outer. In order to explain this we may assume that the protoplasm consists of layers, the outer surface, $X$, differing from the inner surface, $Y$, and from the body of the protoplasm, $W$. We should then have the unsymmetrical chain

$$
\operatorname{sap}|X| W|Y| \operatorname{sap}
$$

which could produce an electromotive force.

If the two surfaces of such a very thin layer of protoplasm can be different, it is of fundamental significance for the theory of the nature of living matter. 